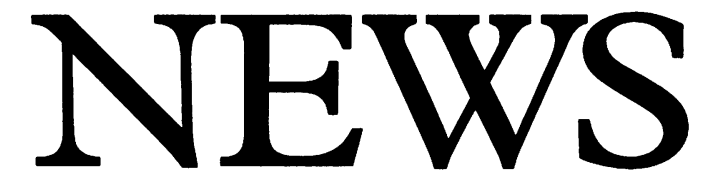

\section{Caring for the}

\section{carers}

People who care for elderly or disabled relatives at home should be given a weekly allowance and a fortnight's holiday a year, says the BMA. The association says that a moderate increase in state benefits for Britain's 6.8 million carers could save taxpayers money in the long run.

The BMA's recommendations come in a report that cites several reasons why the current level of care provided by carers may not be maintained. It notes that the current divorce rate may lessen people's willingness to provide care, and it warns: "The dispersal of families may also pose a very real threat to current levels of caring. Employment associated migration of children to other parts of the UK, or abroad, makes caring more difficult to arrange and more expensive."

The association's report coincides with a second report on the plight of carers from Scope (formerly the Spastics Society). This shows that $57 \%$ of carers interviewed in a survey had faced financial hardship at some time. Almost half had stopped saving or had used up existing funds and had gone without holidays. Three quarters of the carers surveyed said that their health had suffered, with more than a third reporting that they had felt unwell during the previous month.

Scope found that many carers experienced emotional stress and admitted that they had sometimes neglected other members of their family. Almost two thirds said that they did not get enough support from the state. The charity's chief executive, Ann Robinson, said: "Carers save the country a fortune. But, as this report shows, carers pay a huge cost themselves. Their careers suffer, they experience financial hardship, and they are all too often stressed and unwell. The constant struggle erodes both carers' ability to continue in a caring role and their sense of wellbeing."

Another charity, Carers National Association, said that it had calculated that if just one in 10 carers felt unable to continue caring then the cost of funding alternative care would amount to $£ 2$ bn a year. The charity's director, Jill Pitkeathley, said: "These figures demonstrate that it makes sound economic sense to provide carers with the support they need. A small amount of help for carers who are already experiencing health and financial difficulties can help prevent their situation becoming critical. Carers are reasonable people making reasonable demands for support."

The Carers National Association is supporting the Carers Recognition and Services Bill, which had its second reading in the

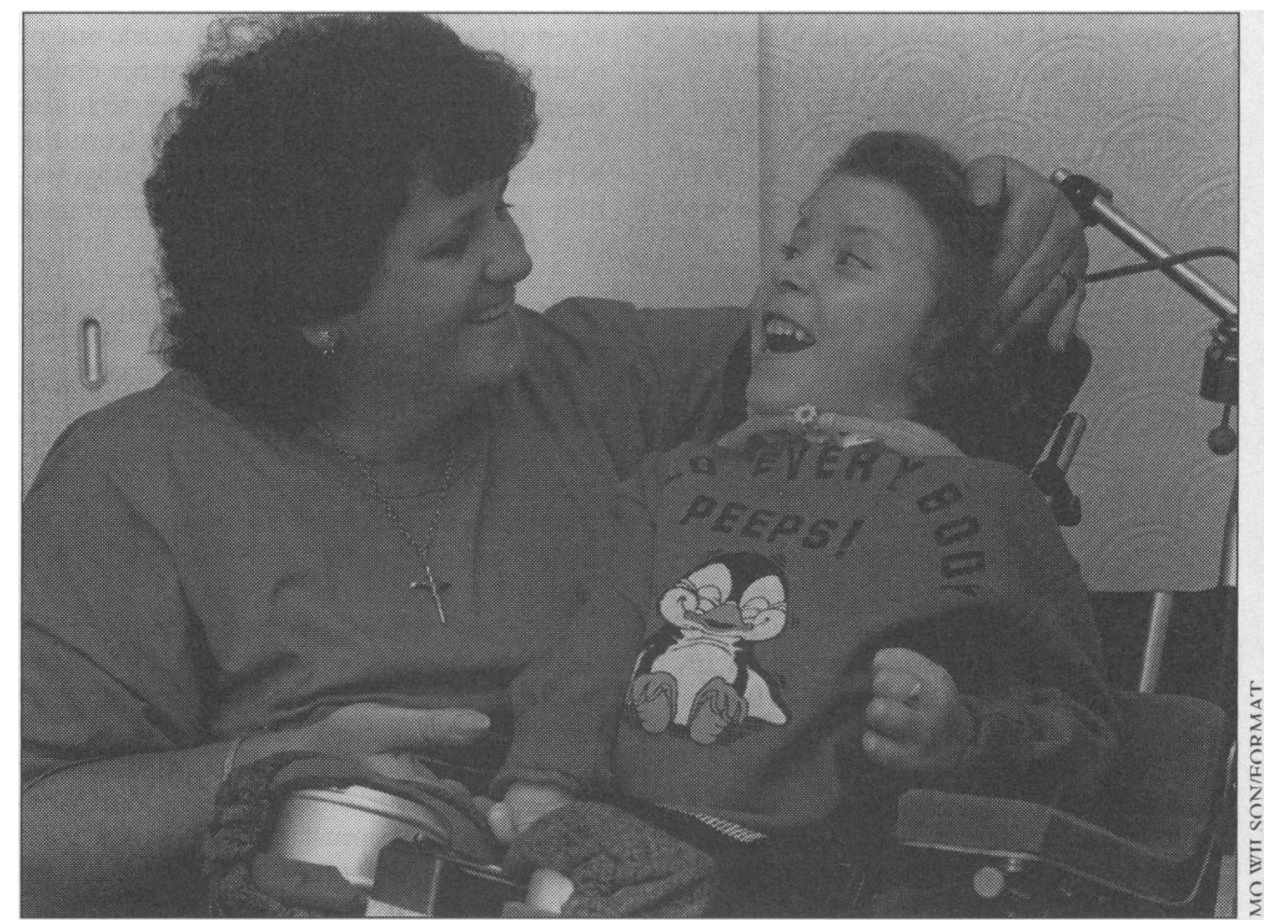

There are nearly seven million carers in Britain

House of Commons last week. The bill, which is supported by the government, requires councils to assess the needs of carers and provide them with support. -CLAUDIA COURT, BMF

Taking Care of the Carers is available from the BMA, BMA House, Tavistock Square, London WC1H 9JP.

Disabled in Britain: Behind Closed Doors is available from Scope, 12 Park Crescent, London WIN 4EQ price $£ 4.95$.

\section{Swedish cancer survey: one in three patients survive}

A recent Swedish survey shows that 10 years after a diagnosis of cancer the average survival rates are $30 \%$ for men and $43 \%$ for women, with considerable differences between cancers. The survey (Acta Oncologica 1995; 34 (suppl 4): 1-124) was carried out by the National Board of Health and Welfare and is claimed to be one of the most comprehensive of its kind. Based on information stored in the national cancer register, which was set up 40 years ago, it is a study of all cases of cancer diagnosed in Sweden between 1961 and 1989, with follow up extending to 1991 .

Professor Måns Rosén, who led the project, said that the study differed from previous ones in its size and length of follow up. Data two, five, 10,15 , and 20 years after the discovery of cancer in 773000 patients were analysed to determine the survival rate, and 36 types of cancer were included. The findings show rates of survival ranging from 1$2 \%$ in the case of liver cancer to $86 \%$ for testicular cancer. Patients found to have cancers of the breast and prostate have lower survival rates than the general population even after 19 years; the few who survive lung cancer can be considered to be cured after seven years.

The survey found evidence of substantial progress in the treatment of childhood leukaemia, Hodgkin's diseàse, testicular cancer, and malignant melanoma over the past 30 years, even though these constitute only $3 \%$ of all registered cases of cancer. The survival prospects for patients with the most common types of cancer have increased at a more moderate pace, while malignant tumours of the liver and pancreas are as deadly as they were 30 years ago.

The general prognosis is best for children and young people, and women seem to have a higher survival rate than men. Better care and earlier detection are considered to be the main reasons for the positive developments over the years covered by the survey, while more effective treatments probably play a less prominent part.-AGNETA MARIA LEWIS, freelance journalist, Stockholm 


\section{Headlines}

US recommends counselling of pregnant women: The US Centers for Disease Control and Prevention recommends that the four million women who become pregnant each year should be counselled and tested for HIV infection. This follows a finding that zidovudine can prevent mother to baby transmission of HIV.

Finland bans smoking at work: From 1 March a Finnish law has banned smoking in canteens at public and privately run factories and other workplaces. As most employers cannot afford separate smoking areas the law is a total ban on smoking at work.

Influenza activity rises in Britain: The UK Communicable Disease Surveillance Centre reports that the weekly consultation rate for "influenza and flu-like illness" rose from about 40 per 100000 population in the last week of December 1994 to 159 in the sixth week of 1995.

More cases of tuberculosis reported in Britain than predicted: The UK Communicable Disease Surveillance Centre reports that about 8000 more cases of tuberculosis were notified between 1988 and 1993 than was expected from previous trends. Most increases were in large conurbations.

Risk of malaria at airports increases in France: The French Academy of Medicine has reported that seven people were infected with malaria in or near Charles de Gaulle airport. Most were airport employees who were infected by mosquitos from endemic countries. The academy recommends more thorough disinfection of planes.

Closure of Guy's Hospital deferred: The merger of Guy's and St Thomas's Hospitals could be deferred after Lambeth, Southwark, and Lewisham Health Commission recommended that the transfer of the accident and emergency and short stay services from Guy's to St Thomas's should be deferred until 1999.

NHS wins tender for Welsh cardiac centre: Morriston Hospital NHS Trust has been awarded the tender against private bidders to build an $£ 8.5 \mathrm{~m}$ cardiac centre and run the $66.5 \mathrm{~m}$ a year services. This is the first time that core clinical services have been subject to open competition.

\section{BMA council backs GPs' out of hours efforts}

The BMA's council has given the chairman of the General Medical Services Committee overwhelming support over the committee's attempts to solve the issue of work out of hours. Dr Ian Bogle, the committee chairman, told the council last week that the GMSC had received an invitation from the NHS Executive to resume talks. If negotiations are unsuccessful he will ask the council to endorse a package of sanctions.

Any sanctions will be reported first to the GMSC, and no steps will be taken before general practitioners are balloted.

But Dr Bogle said: "They are intended to bring measured and increased pressure on the government to prevent the current policies resulting in the collapse of the out of hours service." A new sanction would be added each month until the issue was resolved.

Dr Bogle refused to divulge details of the sanctions, but because most of the measures would be irreversible and are intended to have a permanent effect he said that it would be important for doctors to act responsibly. "Our sanctions must not harm patients, and we must not put at risk individual doctors or practices," he said. As out of hours work was intended for emergencies, patients would continue to have the best possible care, diagnosis, treatment, and referral services. Because much of general practitioners' work was outside their contractual obligations this goodwill could be withdrawn.

Dr Bogle assured the council that all the plans had been approved by the association's solicitors and that no steps would be taken that could threaten the BMA's assets. Any measures would be supported by a parliamentary campaign.

Although about half of all general practitioners now have access to a commercial deputising service and about one in 12 doctors use a cooperative service, many

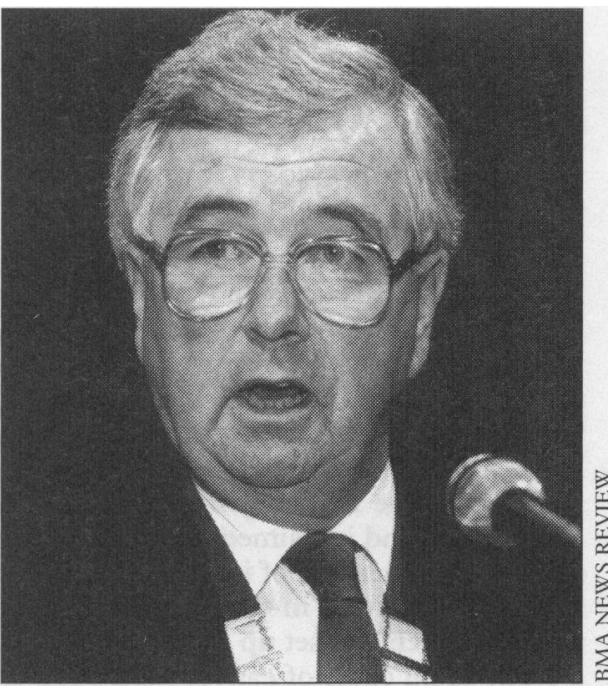

The BMA council supported Dr Ian Bogle doctors have no choice but to do their own out of hours work. The outcome of negotiations in 1994, the GMSC's chairman said, had been a basic allowance for out of hours work of $£ 2000$ and a uniform fee for night visits of $£$.

The GMSC had rejected this unanimously (26 November 1994, p 1392). The review body's report for 1995 made no recommendation for extra money for out of hours work, and the review body had refused to price the out of hours component of the contract.

Dr Bogle told the council that his committee's agenda for resuming negotiations comprised the identification of the out of hours part of the contract, the facility for doctors to opt out of out of hours work, support for rural doctors, an acceptable fee scale, and a commitment to a nationwide campaign to encourage patients to use out of hours services more responsibly.

The Department of Health said that it hoped that discussions would resume this week.-LINDA BEECHAM, $B M f$

\section{Hong Kong doctor cleared of plagiarism}

An epidemiologist at the University of Hong Kong has won a battle to keep his job after rulings by the colony's high court and appeal court that he plagiarised a colleague's questionnaire. Dr Lam Tai Hing, a reader in the university's department of community medicine, was found not guilty of "disgraceful or dishonourable" conduct after an inquiry by a committee of six professors. The decision follows a $\$ H K 16 \mathrm{~m}(£ 1.3 \mathrm{~m})$ legal wrangle between Dr Lam and a colleague, Dr Linda Koo, which has rocked the world of epidemiology and led to the first court ruling anywhere that a research questionnaire may be protected by copyright and confidentiality.

Dr Lam and Dr Koo, a lecturer in the department, started separate research in the early 1980 s into the high incidence of lung cancer among non-smoking Chinese women. Dr Koo, who began her research first, accused Dr Lam of using her questionnaire as a basis for constructing his own. After attempts by the university to mediate failed, Dr Koo and her coresearcher, John Ho, honorary professor of radiation oncology at the university, issued a writ against $\mathrm{Dr}$ Lam, claiming breach of copyright and misuse of confidential information.

The high court case centred on the degree of similarity between the two questionnaires and the extent to which researchers in epidemiology sought to keep their questionnaires confidential.

Dr Koo's chief expert witness, Robert Maclennan, senior principal research fellow with the Queensland Institute of Medical Research in Australia, claimed that few researchers would share questionnaires at an early stage. Dr Lam's expert, Professor 
Richard Peto, director of the Cancer Studies Unit at Oxford University, argued that there was little similarity between the questionnaires and that it was normal practice to share information from questionnaires.

After a nine week trial the high court judge, Mr Justice Bokhary, concluded that Dr Lam had made considerable use of the Koo questionnaire, infringing the plaintiffs' copyright and breaching their confidentiality. He also made a finding that Dr Lam had obtained it "surreptitiously." He awarded damages-later fixed at $\$$ HK500000 (£41 600)-to Dr Koo and Professor Ho.

The Medical Defence Union backed Dr Lam in the high court but was unwilling to fund an appeal, so Dr Lam launched an appeal using the money built up in his university pension. The appeal court upheld the judge's ruling but said that there was no evidence to support a finding that Dr Lam "stole" the document.

Following the appeal court's judgment, the university set up a committee to inquire into Dr Lam's conduct and determine whether he should be dismissed. The committee, which looked at the matter from the beginning and took written and oral evidence, concluded that there was no evidence that Dr Lam had stolen the questionnaires or obtained them in any underhand manner, that his questionnaire was not copied from the Koo questionnaire, and that there was no evidence that he had made improper use of the questionnaire.

At the request of Dr Lam's QC, John Griffiths, leading epidemiologists around the world had been asked to comment for the committee on the degree of similarity between the Koo and Lam questionnaires and on the question of copyright or confidentiality in questionnaires for epidemiological research.

The committee considered letters from 25 epidemiologists, all of whom said that the questionnaires were quite dissimilar and doubted that one could have been copied from the other.

The committee "noted that a clear majority view expressed to it by eminent epidemiologists and other scientists was that in the 1980 s there was no copyright or confidentiality in questionnaires and the practice was of the exchange and use of such material. However, some hold the view that questionnaires should be treated as confidential before the results are published, if confidentiality was claimed by the author."

Professor Peto said: "Two separate questions have unfortunately got mixed up in this case: whether epidemiological techniques or questionnaires should be considered to be copyright and whether in this absurd instance there has been any breach of copyright or appropriate standards of academic behaviour. In fact there wasn't any breach-the questionnaires were completely dissimilar. At present epidemiologists still share questionnaires pretty freely among each other, to the general benefit of medical research. I can see many disadvantages and few, if any, advantages in abandoning this tradition."-CLARE DYER, legal correspondent, $B M f$

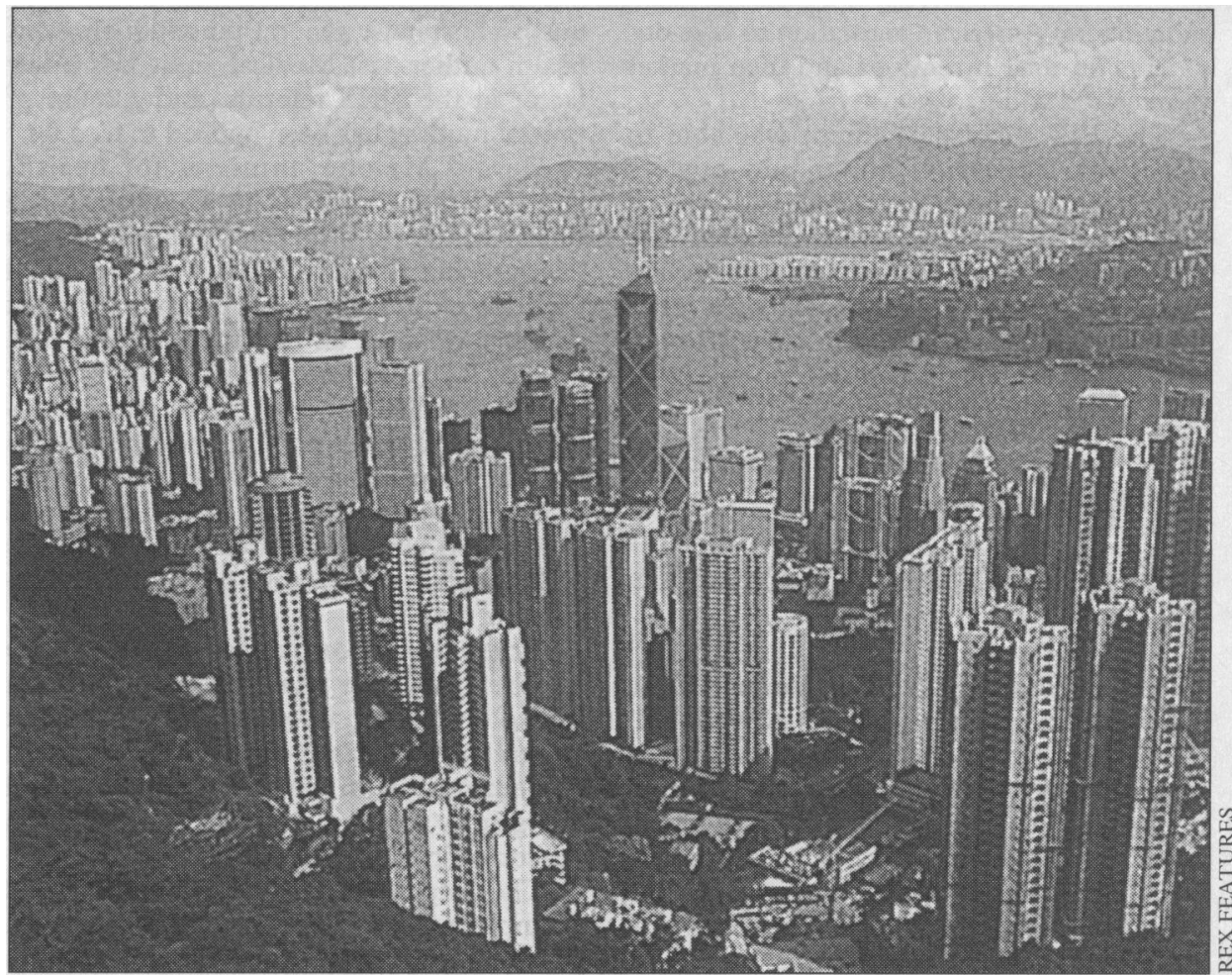

Hong Kong - scene of a legal battle over epidemiological questionnaires

\section{Brussels rejects biotechnology directive}

European Union legislators and the pharmaceutical industry are desperately analysing the impact of the European parliament's unexpected decision on 1 March to reject plans setting common standards for the patenting of biotechnological inventions.

The parliament's rejection of the draft legislation by 240 votes to 188 with 23 abstentions ends seven years of effort designed to balance respect for the dignity of life with the creation of a legal framework to encourage biotechnological research and commercial development in the union.

The rejection surprised most parliamentary observers as it seemed that, a few weeks before, a small delegation of senior European MPs (MEPs) had ironed out their final differences with member governments and built in sufficient ethical safeguards.

These had specifically stated that the human body, including germ cells and products resulting directly from conception, must be excluded from patent legislation. The draft legislation also excluded germ gene treatment and processes for modifying the genetic identity of animals that might cause them suffering "in so far as the suffering or physical handicaps inflicted on the animals concerned are out of proportion to the objective pursued."

But lobbying by environmental groups, particularly Greenpeace, caused many MEPs to consider rejecting the scheme. Its fate was finally sealed when most Socialist members - the largest political group in the parliament - switched sides and voted against the legislation, which they had earlier indicated they could support.

The German Green MEP Hiltrud Breyer spoke for opponents of the draft law when she told her colleagues: "To allow patenting of parts of living bodies, whether they are transformed or not, is to offer human life as fodder for economic interests. It is a violation of human dignity."

The setback has been strongly criticised by many people in the pharmaceutical industry, who argue that the low level of protection of intellectual property available to biotechnology inventions in the union is a factor contributing to the low rate of job creation and investment in the industry.

The Senior Advisory Group Biotechnology, which represents 32 companies with a combined total annual turnover of over $\$ 300$ bn $(£ 200000 \mathrm{~m})$, said the parliament's vote "sends a negative political signal to investors that will further reduce the attractiveness of the union as a place for doing business in the new technologies."

The internal market European commissioner, Mario Monti, was also unable to disguise his disappointment, echoing the view that the absence of legal protection now put companies based in the EU at a competitive disadvantage in relation to their American and Japanese competitors. The collapse of the union's initiative means that the present arrangements, whereby biotechnological products may be patented in one EU country but not in another, remain in place.

Some EU officials believe that opponents of the legislation failed to appreciate how restrictive it was, providing safeguards that would have prevented the kind of genetic engineering some feared was being encouraged. They predict that multinational pharmaceutical companies will now use the 
more liberal American legislation to take out patents on their inventions and then market these world wide.

The European parliament was able to reject the legislation under new powers given to it by the Maastricht treaty, which provides it, not EU governments, with the final say on certain policy areas, including the single market. It is the second time it has used these powers to reject a draft union law.- RORY WATSON, European

\section{BMA to run clinical audit centre}

A consortium led by the BMA and the Royal College of Nursing has won a government contract to set up and run a new centre to disseminate information derived from clinical audit. The centre will be the focal point for disseminating good practice established through local evaluation. The contract, initially for three years, is worth $£ 200000$ a year

The aim of the new centre is to extend into the NHS the benefits of audits carried out by hospitals, general practitioners, and health authorities. Medical audit was a key factor in the NHS reforms, and $£ 260 \mathrm{~m}$ of central funding has been applied to it so far.

Gerald Malone, minister for health, announced the contract in a speech to the Social Market Foundation. He said it was encouraging that the BMA and the Royal College of Nursing had chosen to work together on such an important project and added: "This is another example of how patients can benefit from health professionals of all disciplines pooling their experience in order to achieve effective clinical results. It is common sense that if we identify and share good clinical practice throughout the NHS patients will benefit from higher standards of care."

The audit information centre will be another link in a chain of research data being provided by the UK Cochrane Centre in Oxford, the centre for reviews and dissemination in York, and the United Kingdom clearing house on health outcomes in Leeds.

The Department of Health cites several examples of audit leading to changes in local practice: a plan of shared care between primary and secondary care for the management of gastrointestinal bleeding reduced the death rate from $13 \%$ to $4 \%$, organisational change reduced the time taken for reports on $x$ ray films to be received by accident and emergency departments from 10 days to two days, $x$ ray films of nasal fractures are no longer obtained routinely in accident and emergency departments because it was found that the results did not influence treatment, and administration of intravenous antibiotics is given within one hour of planned time in $60 \%$ of cases as opposed to $25 \%$ of cases when this was first audited.

Mr Malone described the new information centre as "one of the cornerstones of the government's long term strategy for the development of clinical audit."

The BMA said that the capability that the centre represented would be "unparalleled" and added: "We believe that there is no other way of translating the Department of Health's policy on clinical audit from a paper statement into a living policy in daily practice except by this partnership of professions driving the policy, harnessing the power of information and communication technology, to achieve the goal of truly multi disciplinary, clinically led, and effective clinical audit."-JOHN WARDEN, parliamentary correspondent, $B M \mathcal{F}$

\section{Focus: Sydney}

\section{Three strikes and out for the Australian Tobacco Institute?}

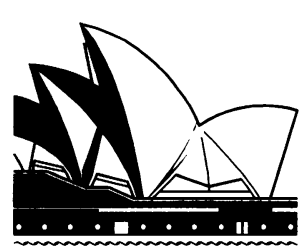

The tobacco industry in Australia has twice recently been castigated for misleading the public in its attempts to defend the indefensible. Recent public hearings of an Australian senate committee examining "the tobacco industry and the costs of tobacco related illness" suggest that the industry is at it again. The Hansard records from the hearings provide a catalogue of faux pas by the industry.

The tobacco industry has long been huddled in its bunker, sneaking out to trumpet the arrival of an international scientific confabulator or to whinge about the latest policy squeeze. For its spokesmen have had virtual lockjaw in any public forum. Most journalists seem to have decided that they are poor media talent, so, in the words of a US industry spokesman, they "are forever dogged with being at the bottom of the story in a chip shot quote taken out of context."

In the past few years the industry's main lobbying agency, the Tobacco Institute of Australia, has blundered monumentally when venturing into print. In 1991 it was found by the courts to have engaged in misleading and deceptive advertising. It ran advertisements claiming "there is little evidence and nothing which proves scientifically that cigarette smoking causes disease in non-smokers" (see BMF 1991;302:943-5; 1993;306:120-2). The industry is estimated to have forked out $\$ A 7 \mathrm{~m}(£ 3.2 \mathrm{~m})$ in legal costs. Also in 1991 the Advertising Standards Council ruled that in a press advertisement the institute had fabricated the results of an opinion poll which purportedly showed overwhelming community support for tobacco sponsorship (the phone poll was recording only "yes" votes, while the advertisement stated that $10 \%$ of callers voted "no").

The recent Senate committee hearings show that the institute still doesn't seem to have learnt its lesson. During my own evidence I drew attention to a complaint currently before the Trade Practices Commission about a statement in a booklet produced by the institute, Clearing the Air for All. Environmental Tobacco Smoke. Another Side of the Story. Early in the booklet it states: "In short... [a] non-smoker's exposure to [environmental tobacco smoke] is a little like pouring a nip of vodka into an olympic size swimming pool and then after it had all been mixed in, trying to find the vodka." A typical olympic swimming pool contains 2.4 million litres, and a nip of spirits $30 \mathrm{ml}$. The institute is thus proposing that a non-smoker's exposure from passive smoking is 80 million times less than active smokers' exposure to tobacco smoke. By contrast, the United States Environmental Protection Agency states that "Cotinine levels in nonsmokers exposed to [environmental tobacco smoke] are approximately $1 \%$ of the levels in active smokers." Some might think it unreasonable to suggest that a ratio of $1: 80000000$ is analogous to one of $1: 100$.

The very pregnant chief executive of the Tobacco Institute of Australia, Donna Staunton (who confirmed to a questioning journalist that, yes, she had stopped smoking during her pregnancy despite insisting to the committee that there was only "a statistical association" between smoking and disease), was questioned about the vodka statement. She replied that it was "simply an example of a dilution factor. It was never meant to be a precise calculation, and it does not read as a precise calculation ... I think it is a reasonable analogy to make." If the Trade Practices Commission rules that the institute has again misled the public it will be the third time.

Ms Staunton was also asked if she was familiar with the 40 year follow up of British doctors' smoking habits published by Richard Doll's group last year in the $B M F$. She replied, "I must admit I have not had the opportunity to read it." Shortly afterwards, the New South Wales Cancer Council helpfully sent her a copy by certified mail. It might help the institute to avoid confusing the public in future. - SIMON CHAPMAN, associate professor of public health and community medicine, University of Sydney 